\title{
DYNAMICAL BEHAVIOR OF A STAGE STRUCTURED ECO-EPIDEMIOLOGICAL MODEL
}

\author{
SHASHI KANT AND VIVEK KUMAR
}

\begin{abstract}
In this paper, a stage structured eco-epidemiological model with linear functional response is proposed and studied. The stages for both prey and predator have been considered. Infection occurs in the prey population only. The proposed mathematical model consists of five nonlinear ordinary differential equations to describe the interaction among juvenile prey, adult prey, infected prey, juvenile predator and adult predator populations. The model is analyzed by using linear stability analysis to obtain the conditions for which our model exhibits stability around the possible equilibrium points.
\end{abstract}

Mathematics subject classification (2010): 70Kxx, 34Cxx.

Keywords and phrases: Stage structured population, local stability.

\section{REFERENCES}

[1] A. Lotka, Elements of physical biology Williams and Wilkins, Baltimore, 1925.

[2] Banshidhar Sahoo and Swarup Poria, Diseased prey predator model with general Holling type interactions, Applied Mathematics and Computation, 226, (2014), $83-100$. http://dx.doi.org/10.1016/j.amc.2013.10.013.

[3] B. Mukhopadhyaya and B. Bhattacharyya, Dynamics of a delay-diffusion prey-predator Model with disease in the prey, J. Appl. Math and Comp., 17, 12(2005), $361-377$. http://dx.doi.org/10.1007/BF02936062.

[4] B. Liu et al, The effects of impulsive toxicant input on a population in a polluted environment, J. Biol. Syst., 11, 3(2003), 265 - 274. http://dx.doi.org/10.1142/S0218339003000907.

[5] Birkhoff, G. , Rota, G.C.: Ordinary Differential Equations. Ginn, Boston, 1982.

[6] Chao Liu et al, Dynamical behaviour in a stage-structured differential-algebriac prey-predator model with discreate time delay and harvesting, J. Comp. Appl. Math., 231, 2(2009), 612-625. http://dx.doi.org/10.1016/j.cam.2009.04.011.

[7] C.S. Holling, The components of predation as revelaed by a study of small mamal predation of the European pine sawfly, Canad. Entomologist, 91, (1959), 293-320.

[8] C.S. Holling, Some chararacteristics of simple types of predation and parasitism, Canad. Entomologist, 91, (1959), 385-395.

[9] J.H. Dawes and M.O. Souza, A derivativation of Holling's type I,II and III functional responses in predator-prey system, J. Theor. Biol., 327, (2013), 11-22. http://dx.doi.org/10.1016/j.thbi.2013.02.017.

[10] D. Greenhalgh and M. Haque, A predator-prey model with disease in the prey species only, Math. Methods Appl. Sci., 30, 8(2007), 911-929. http://dx.doi.org/10.1002/mma.815.

[11] D.L. Deangenis et al, A model for trophic interaction, Ecology, 56,(1975), 881-892.

[12] Guang-Ping Hu and Xiao-Ling Li, Stability and Hopf bifurcation for a delayed predator-prey model with disease in the prey, Chaos, Solitons and Fractals, 45, (2012), 229-237. http://dx.doi.org/10.1016/j.chaos.2011.11.011.

[13] M. Haque, E. Ventuirino, An ecoepidemiological model with disease in predator: the ratio-dependent case. Math. Meth. Appl. Sci., 30, (2007), $1791-1809$.

[14] M. Haque, E. Ventuirino, The role of transmissible diseases in Holling-Tanner predator-prey model. Theor Popul Biol, 70, 3(2006), 273 - 88. 
[15] V.S. Ivlev, Experiment Ecology of the feeding of fishes (Yale University Press, New Haven, C.T., 1961.

[16] J. Chattopadhyay, O. Arino , A predator-prey model with disease in prey, Non Linear Analysis, 36, (1999), $747-766$.

[17] Jian-Jun-Jiao, Permananece and global attractivity of stage-structured predator-prey model with continous harvesting on predator and impulsive stocking on prey, Appl. Math. Mech.(Engl. Ed.), 29, 5(2008), 653-663. http://dx.doi.org/10.1007/S10483-008-0509-X.

[18] J.R. Beddington, Mutual interference between parasites or predators and its effect on searching efficiency, J. Animal Ecology, 44, (1975), 331-340.

[19] J. Cui and X. Song, Permanence of predator-prey system with stage structure, Discrete Contin. Dyn. Syst. Ser. B, 4 3(2004) 547-554. http://dx. doi .org/10.3934/dcdsb. 2004.4.547-554

[20] Jawdat Alebraheem, Yahya Abu Hasan, Dynamics of a two predator and one prey system, Comp. Appl. Math, (2014). http://dx.doi.org/10.1007/s40314-013-0093-8

[21] T.K. Kar, S. Jana, A Theortical study on mathematical modeling of an infectius disease with application of optimal control, Biosystems, (2012).

http://dx.doi.org/10.1016/j.biosystems.2012.10.003

[22] Litao Han et al, Four Predator Prey Models with Infectious Diseases, Mathematical and Computer Modeling, 34, 7-8(2001), 849 - 858. http://dx. doi.org/10.1016/S0895-7177 (01) 00104-2.

[23] Linfei Nie and Zhidong Ting, Singular perturbation method for global stability of ratio dependent predator-prey model with stage structure for the prey, Electronic Journal of Differential Equations, 86, (2013) 1-9. http://ejde.math.txstate.edu or http://ejde.math.unt.eduftpejde.math.txstate.edu.

[24] Liming Cai, Xinyu Song, Permanence and stability of a predator-prey system with stage structure for predator, J. Comp. Appl. Math., 201, (2007), 356-366.

[25] M.P. Hassell and C.C. Varley, New inductive population model for insect parasites and its bearing on biological control, Nature, 223,(1969), 1133-1137.

[26] L. Maoxing et al, An Impulsive predator-prey model with communicable disease in the prey species only, Non Linear analysis: Real World Applications, 10, (2009), 3098-3111.

http://dx.doi.org/10.1016/j.nonrwa.2008.10.010.

[27] M. Haque and E. Venturino, Increase of the prey may decrease the healthy prtedator population in presence of a disease in predator, HERMIS 7,(2006), 38-59. WWw . aueb. br/pympe/hermis-volume-7/DIFF-INTEGRAL-EQUATIONS/HAQUE-VENTURINO-1.pdf .

[28] W.W. Murdoch, C.J. Briggs, R.M. Nisbet, Consumer-Resource dynamics Princeton: Princeton University Press, 2003.

[29] M. Nagumo, Uber die Lage der Integralkurven gew onlicher Differentialgeichungen, Proc. Phys. Math. Soc. Japan., 24, (1942), 555.

[30] D. Mukherjee, Persistence Aspect of a predator-prey model with disease in the prey, Differ Equ Dyn Syst,(2014). http://dx.doi.org/10.1007/s12591-014-0213-y.

[31] Paul Georgescu and Ying-Hen Hsieh, Global dynamics of a predator-prey model with stage-structure for the predator, SIAM J. Appl. Math., 67, 5(2007), 1379-1395. http://dx.doi.org/10.1137/06070377.

[32] P.H. Crowley and E.K. Martin, Functional responses and interference within and between year classes of a dragonfly population, J. North American Benthological Soc., 8, (1989), 211-221.

[33] Pallav Jyoti Pal, Mainul Haque, Prashanta Kumar Mandal, Dynamics of a predator-prey model with disease in the predator Math. Meth. Appl. Sci., (2013). http://dx.doi.org/10.1002/mma. 2988.

[34] Raid Kamel Naji and Kawa Ahmed Hasan, The dynamics of prey-predator model with disease in the prey, J. Math. Comput. Sci., 2, 4(2012), 1052-1072.

[35] R. Arditi and L.R. Ginzburg, Coupling in predator-prey dynamics: Ratio-dependence, J. Theor. Bio. 139, (1989), 311-326.

[36] Rui Xu et al, Periodic solutions of a delayed predator prey model with stage structure for predator, $J$. Appl. Math., 3 , (2004), 255-270. http://dx.doi.org/10.1155/S1110757X04308090.

[37] G.P. Samanta, Analysis of a delay nonautonomous predator-prey system with disease in the prey. Non Linear Analysis: Modeling and Control, 15, 1(2010), 97-108. www. lana.lt/journal/36/samanta.pdf.

[38] S.A. Gourley, Y. Kuang, A stage structureed predator-prey model and its dependence on maturation delay and death rate, J. Math. Bio., 49, 2(2004), 188-200. http://dx.doi.org/10.1007/soo285-004-0278-2. 
[39] Soovoojeet Jana and T.K. Kar, Modeling and analysis of a prey-predator system with disease in the prey, Chaos, Solitons and Fractals, 47, (2013), 42-53.

http://dx.doi.org/10.1016/j. chaos.2012.12.002.

[40] Shengqiung Liu, Edoardo Beretta, A stage-structured predator-prey model of Beddington-DeAgelis type, SIAM J. Appl. Math., 66, 4(2006), 1101-1129. http://dx.doi .org/10.1137/050630003.

[41] Swarnali Sharma and Samanta G.P., Dynamical behaviour of a two prey and one predator syatem, Differ Equ Dyn Syst, 22, 2(2014), 125-145. http://dx. doi .org/10.1007/s12591-012-0158-y.

[42] Sana SS, Purohit D, Chaudhury KS, Joint project of fishery and poultry- a bioeconomic model, Appl Math Model., 36, (2012), 72-86.

[43] Santosh Biswas, Sudip Samanta and Joydev CHattopadhyay, A model based theortical study on cannibalistic prey-predator system with disease in both populations, Differ Equ Dyn Syst,(2014). http://dx.doi.org/10.1007/s12591-014-0211-o.

[44] Tongqian Zhang et al, A stage-structured predator-prey SI model with disease in the prey and impulsive effetcs, Mathematical Modelling and Analysis, 18, 4(2013), 505-528. http://dx.doi.org/10.3846/13926292.2013.840866.

[45] T. Zhang et al, The dynamics of a high dimensional delayed pest management model with impulsive pesticide input and harvesting prey at different fixed moments, Nonlinear Dynamics, 64, 1(2011), 1-12. http://dx.doi.org/10.1007/s11071-010-9840-1.

[46] V. Volterra, Variazioni e fluttauazionidel numero d individui in species animals conviventii, Mem Acd. Linciei, 2 , (1926), 31 - 113.

[47] V. Lakshmikantham, D. Bainov and P. Simeonov, Theory of Implulsive Differential Equations, World Scientific, Singapore, 1989.

[48] Venturino E., Epidemics in predator-prey models: disease in predators, IMA J. Math Appl. Med. Bio., 19, (2009), 185-205.

[49] W.O. Kermack and A.G. Mckendrick, Contributons to the mathematical Theory of Epidimics, Part 1, Proc. Roy. Soc. A, 115, 5(1927), 700-721.

[50] W.Wang and L. Chen, A predator-prey system with age structure for predator, Comp. Math. Appl., 33, 8(1997), 83-91. http://dx.doi.org/10.1016/So898-1221(97)00056-4.

[51] W.G. Aiello et al, A time-delay model of single species growth with stage structure, Math. Biosci., 101, 2(1990), 139-153. http://dx.doi.org/10.1016/0025-5564(90)90019-U.

[52] X. Meng and L. Chen, A stage structured SI eco-epidemiological model with time dealy and implusive controlling, J. Syst. Sci. Complex, 21, 3(2008), 427-440. http://dx.doi.org/10.1007/S11424-008-9214-8.

[53] Xu et al, Perisistence and global stability of a ratio dependent prey model with stage-structure, Appl. Math. Comp., 158, 3(2004), 729-744. http://dx.doi.org/10.1016/j.amc.2003.10.012.

[54] Xiaohong Tian and Rui Xu, Global dynamics of a predator-prey system with Holling type II functional response, Nonlinear Analysis: Modelling and Control, 16, 2(2011), 242-253. Www. lana.lt/journal/41/NA16210.pdf.

[55] Xue Zhang et al, Bifurcations of a singular prey-predator economic model with time delay and stage structure, Chaos Soliton and Fractals, 42, (2009), 1485-1494. http://dx.doi.org/10.1016/j.chaos.2009.03.051.

[56] Xinyu Song et al, A stage-structureed predator-prey model with disturbing pulse and time delays, Appl. Math. Modell., 33, 1(2009), 211-223. http://dx.doi.org/10.1016/j.apm.2007.10.020.

[57] X. Song and L. Chen, Optimal harvesting and stability for a two species competitive system with stage structure, Math. Biosci., 170, 2(2001), 173-186. http://dx.doi.org/10.1016/S0025-5564(00)00068-7

[58] Yanni Xiao, Lansun Chen, Modeling and analysis of a predator-prey model with disease in the prey, Math. Biosci., 171, 1(2001), 59-82. http://dx.doi.org/10.1016/S0025-5534(01)00049-9.

[59] Yonghui Xia et al, Multiple periodic solutions of a delayed stage-structured predator-prey model with non-monotonic functional responses, Appl. Math. Modell.,31, 9(2007), 1947-1959. http://dx.doi.org/10.1016/j.apm.2006.08.012

[60] Y. Kuang and E. Beretta, Global qualitative analysis of a ratio-dependent predator-prey system, $J$. Math. Bio., 36, (1998), 1319-1360.

[61] Zhongui Xiang, A Lotka-Volterra model with impulsive effects on the prey and stage structure on the predator, Appl. Math. Sci.,4, 17-20(2010), 849-856.

www.m-hikari.com/ams/ams-2010/ams-17-20-2010/xiangAMS17-20-2010.pdf 
Differential Equations \& Applications www.ele-math.com dea@ele-math.com 